University of Wollongong

Research Online

Faculty of Engineering and Information

Faculty of Engineering and Information

Sciences - Papers: Part A

Sciences

$1-1-2008$

Numerical analysis of roll deflection for Sendzimir mill

H L. Yu

Northeastern University, hailiang@uow.edu.au

X H. Liu

Northeastern University, liuxh@uow.edu.au

G T. Lee

POSCO

X W. Li

Northeastern University

H D. Park

POSCO

Follow this and additional works at: https://ro.uow.edu.au/eispapers

Part of the Engineering Commons, and the Science and Technology Studies Commons

Research Online is the open access institutional repository for the University of Wollongong. For further information contact the UOW Library: research-pubs@uow.edu.au 


\title{
Numerical analysis of roll deflection for Sendzimir mill
}

\author{
Abstract \\ The present work introduces a new type of numerical analyzing method: the contact element method with \\ two relative coordinates (CEM). The main characteristic of the procedure is elements meshing on the \\ basis of the contact length between objects and that each element has two relative coordinates. The \\ ordinary expression of this procedure is $\operatorname{DX}[\mathrm{CXY}(\mathrm{i})]=\mathrm{D} Y[\mathrm{CYX}(\mathrm{i})]$. Through this method, the CEM function of \\ the 20-high Sendzimir mill and the deflection function expression of every roll are obtained. A \\ computational software SM4SM for the Sendzimir mill has been developed, by which the deflection \\ condition of rolls $\mathrm{S}, \mathrm{O}, \mathrm{I}$, and A can be obviously seen. The results obtained by CEM have also been \\ compared to that by the finite element method. Copyright $\odot 2008$ by ASME.
}

\section{Keywords}

mill, numerical, sendzimir, deflection, roll, analysis

Disciplines

Engineering | Science and Technology Studies

\section{Publication Details}

Yu, H. L., Liu, X. H., Lee, G. T., Li, X. W. \& Park, H. D. (2008). Numerical analysis of roll deflection for Sendzimir mill. Journal of Manufacturing Science and Engineering, Transactions of the ASME, 130 (1), 0110161-1-0110167-7. 


\author{
H. L. Yu ${ }^{1}$ \\ e-mail: yuhailiang1980@tom.com \\ X. H. Liu \\ The State Key Laboratory of Rolling and \\ Automation, \\ Northeastern University, \\ Shenyang 110004, China \\ G. T. Lee \\ POSCO Technical Research Laboratories, \\ Pohang, 790-785, Korea \\ X. W. Li \\ The State Key Laboratory of Rolling and \\ Automation, \\ Northeastern University, \\ Shenyang 110004, China \\ H. D. Park \\ POSCO Technical Research Laboratories, \\ Pohang, 790-785, Korea
}

\section{Numerical Analysis of Roll Deflection for Sendzimir Mill}

The present work introduces a new type of numerical analyzing method: the contact element method with two relative coordinates (CEM). The main characteristic of the procedure is elements meshing on the basis of the contact length between objects and that each element has two relative coordinates. The ordinary expression of this procedure is $D_{X}\left[C_{X Y}(i)\right]=D_{Y}\left[C_{Y X}(i)\right]$. Through this method, the CEM function of the 20-high Sendzimir mill and the deflection function expression of every roll are obtained. A computational software SM4SM for the Sendzimir mill has been developed, by which the deflection condition of rolls $S, O, I$, and A can be obviously seen. The results obtained by CEM have also been compared to that by the finite element method. [DOI: 10.1115/1.2783256]

Keywords: Sendzimir mill, roll deflection, numerical analysis, contact element method

\section{Introduction}

Sendzimir mill is extensively used for rolling stainless steel, silicon steel, etc. To improve the quality and quantity of the strip, a series of research has been carried out. Schneider and Werners [1] studied the roll gap adjusting device of a 20-high Sendzimir mill; Berger et al. [2] introduced the devices of a Sendzimir mill (e.g., hydraulic automatic gauge control (AGC) and automatic flatness control (AFC) system); Dutton [3], Gunawardene [4] paid attention to the shape forecast and control of a Sendzimir mill. However, systematical research about the roll deflection of Sendzimir mill has not been seen thus far.

The condition of roll deflection will affect the strip shape. Researchers have generally studied the strip flatness and profile through analyzing the rolls deflection. Knapiński [5], Jiang et al., [6] and Yuen et al. [7] separately applied finite element method (FEM) and influence function method (IFM) to analyze the roll deflection during rolling process for 4-high mill. However, due to the high ratio of the roll barrel length to the roll diameter and multicontact positions between rolls in a Sendzimir mill, it is difficult to systematically analyze its rolling processes by FEM, $[8,9]$ which will cost much time and computer resources. The IFM is widely used to analyze the rolls deflection, but it is difficult to deal with the unequal contact length between rolls.

Here we present a new numerical analysis method: the contact element method with two relative coordinates (CEM). With this method, roll deflection analysis models were built for the roll system of a Sendzimir mill, and a software, SM4SM (Setup Models for Sendzimir Mill), was developed. The deflection condition of rolls $S, O, I$, and $A$ was also analyzed. A new procedure for analyzing the roll deflection with numerical method was provided through the research.

\footnotetext{
${ }^{1}$ Corresponding author.

Contributed by the Manufacturing Engineering Division of ASME for publication in the Journal of Manufacturing Science and Engineering. Manuscript received November 13, 2006; final manuscript received July 7, 2007; published online February 15, 2008. Review conducted by Steven R. Schmid.
}

\section{Analysis Method and Mathematical Models}

\subsection{Contact Element Method With Two Coordinates}

2.1.1 Element Meshing. Figure 1 shows the meshing between the work roll and the strip and that between the work roll and the first intermediate roll (IMR). Elements are meshed based on the contact length between the strip and the work roll or between the work roll and the first IMR. Each element has two relative coordinates separately on the basis of two contact objects. When the elements are on the contact zone between the work roll and the strip, one of the relative coordinates depends on the strip width, and the other depends on the barrel length of the work roll. The same method is used for dealing with the other contact zone between rolls. The quantity of elements between the work roll and the strip and that between other rolls might be different, and meshing ways can also be different. As shown in Fig. 1, the element width between the work roll and the strip is different, but the element width between the work roll and the first IMR keeps constant.

2.1.2 Element Width. Because the contact length between rolls is different, the widths of elements are variable. Equation (1) shows the element width between the contact objects $X$ and $Y$ (assuming $W_{X}>W_{Y}$ ).

$$
W_{X Y}=\frac{W_{Y}}{N}
$$

2.1.3 Relative Coordinates of Elements. Assuming $W_{X}>W_{Y}$, the relative coordinates of element $i$ between the contact objects $X$ and $Y$ can be given by

$$
\begin{gathered}
C_{X Y}(i)=\frac{W_{X}-W_{Y}}{2.0}+(i-0.5) W_{X Y} \\
C_{Y X}(i)=(i-0.5) W_{X Y}
\end{gathered}
$$




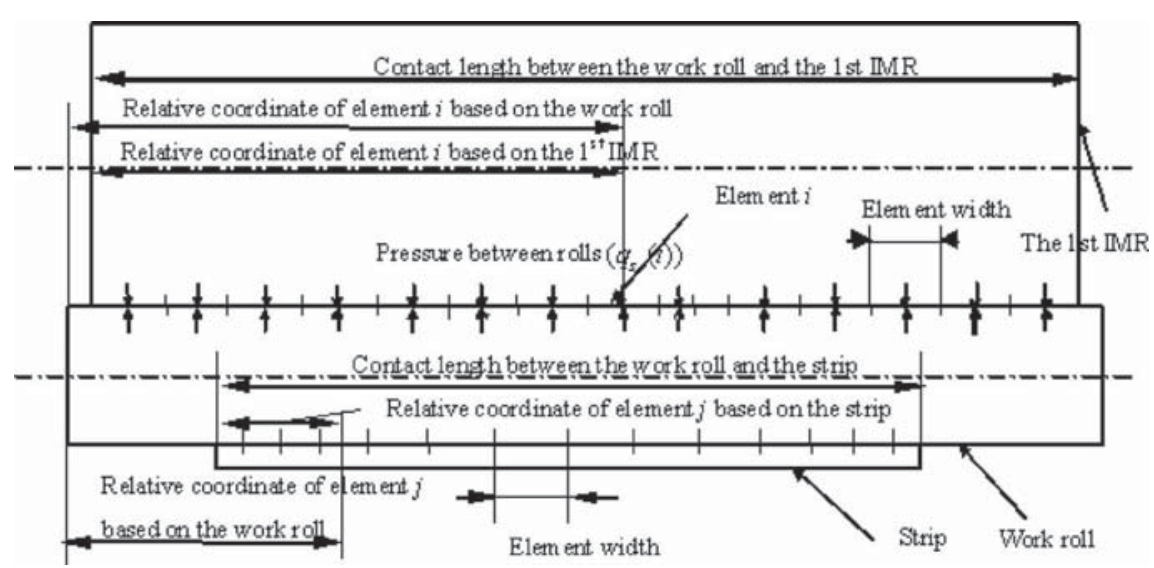

Fig. 1 Element meshing

2.1.4 Coordination Function. During rolling, each element on the contact zone between two contact rolls has the same displacement for the contact rolls, and the coordination equation for the deformation of the roll and the strip is established according to this.

The coordination function of deformation of every element can be described by

$$
D_{X}\left(C_{X Y}(i)\right)=D_{Y}\left(C_{Y X}(i)\right)
$$

\subsection{Mathematical Model}

2.2.1 Rolling Pressure. In a cold-rolling process, the rolling pressure between the work roll and the strip is calculated with the Stone's formula, which is shown as follows:

$$
P_{c p}=f\left(K, t_{c p}, f, l, h_{c p}\right)=\left(K-t_{c p}\right) \frac{e^{f l / h_{c p}}-1}{f l / h_{c p}}
$$

where $l$ can be obtained from

$$
l=\sqrt{R\left(h_{0}-h_{1}\right)+\left[\frac{8 R\left(1-\sigma^{2}\right)}{\pi E}\right]^{2} P_{c p}^{2}}+\frac{8 R\left(1-\sigma^{2}\right)}{\pi E} P_{c p}
$$

2.2.2 Friction Angles Between Rolls of the Roll System. The acting forces and the friction angles between rolls of the roll system of Sendzimir mill are shown in Fig. 2.
According to Ref. [10], the friction angles and the acting forces between rolls are related to the structure of the roll system and the rolling force, which can be obtained from

$$
\left[P_{X}, \alpha_{X}\right]=f\left(P_{N P}, \varphi_{A} \sim \varphi_{L}, v\right)
$$

2.2.3 Roll Flattening Between Rolls. Hertz equation is employed for the calculation of roll flattening between rolls, as shown in

$$
\begin{aligned}
b^{2}= & \frac{4}{\pi} \frac{R_{k} R_{k}^{\prime}}{R_{k}+R_{k}^{\prime}}\left(\frac{1-\sigma_{k}^{2}}{E_{k}}+\frac{1-\sigma_{k}^{\prime 2}}{E_{k}^{\prime}}\right) P \\
\Delta= & \frac{2 P}{\pi}\left[\frac{1-\sigma_{k} 2}{E_{K}}\left(\ln \left(\frac{2 R_{K}}{b}+0.407\right)\right)\right. \\
& \left.+\frac{1-\sigma_{k}^{\prime} 2}{E_{K}^{\prime}}\left(\ln \left(\frac{2 R_{K}^{\prime}}{b}+0.407\right)\right)\right]
\end{aligned}
$$

2.2.4 Roll Deflection. On the assumption that the roll is an elastic beam, by the elastic deformation theory, the roll deflection induced by an assembling force is shown in

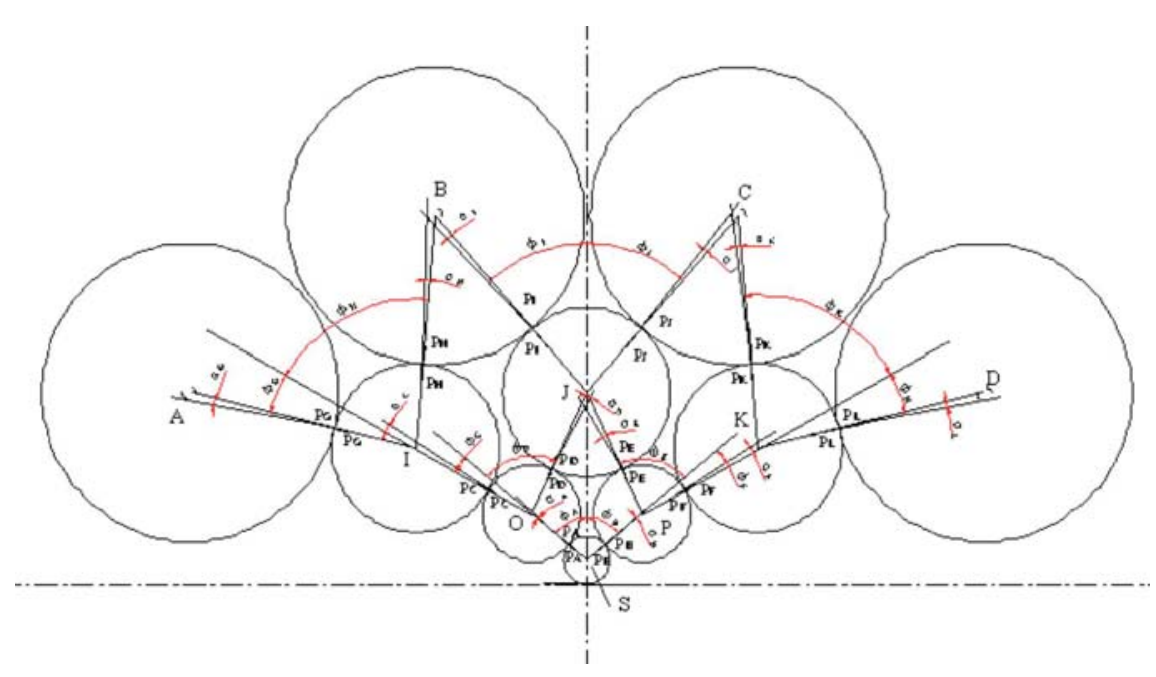

Fig. 2 Acting force between rolls of rolls system of Sendzimir mill 

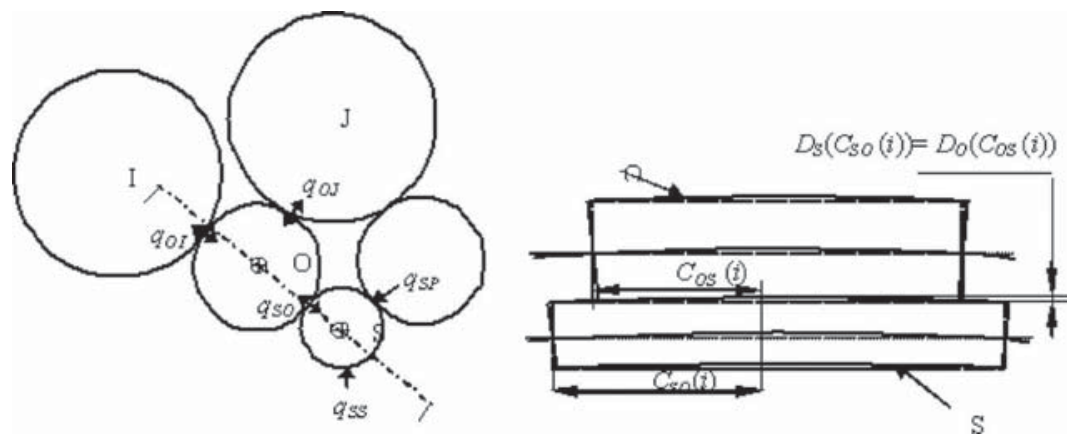

Fig. 3 Deformation between the rolls $S$ and $O$

$$
\begin{aligned}
y(x) & =\mathrm{g}\left(F, l_{1}, L, E, I_{Z}, x\right) \\
& = \begin{cases}-\frac{F x\left(L-l_{1}\right)}{6 E I_{Z} L}\left(x^{2}-L^{2}+\left(L-l_{1}\right)^{2}\right) & \left(0 \leq x<l_{1}\right) \\
-\frac{F x\left(L-l_{1}\right)}{6 E I_{Z} L}\left(x^{2}-L^{2}+\left(L-l_{1}\right)^{2}\right) & \frac{F\left(L-l_{1}\right)}{6 E I_{Z}}\left(x-l_{1}\right)^{3} \\
& \left(l_{1} \leq x \leq L\right)\end{cases}
\end{aligned}
$$

2.2.5 Pressure Between Rolls. The deformation coordination functions can be deduced according to Eqs. (3), (4), and (6)-(8), which are the function for the elements between rolls $S$ and $O, S$ and $P, I$ and $O, J$ and $O$, roll $P$ and $J, P$ and $K, I$ and $A, I$ and $B$, $J$ and $B, J$ and $C, K$ and $C$, and $K$ and $D$. Among these, the deformation coordination function between rolls $S$ and $O$ is deduced as follows.

Figure 3 shows the deformation between rolls $S$ and $O$. In deformation process, the deformation can be divided into two parts: roll deflection and roll flattening. The roll $\mathrm{S}$ deflection is affected by $q_{S S}, q_{S O}$, and $q_{S P}$.

From the Eq. (8), the roll $\mathrm{S}$ deflection in $C_{S O}(i)$ position affected by $q_{S S}$ can be obtained by

$$
\begin{aligned}
D_{S_{-} q_{S S}}\left(C_{S O}(i)\right)= & \mathrm{g}\left(q_{S S}(1) \times W_{S S} \times \cos \left(\varphi_{A}+v\right), C_{S S}(1), W_{S}, E, I_{Z S}, C_{S O}(i)\right) \\
& +\mathrm{g}\left(q_{S S}(2) \times W_{S S} \times \cos \left(\varphi_{A}+v\right), C_{S S}(2), W_{S}, E, I_{Z S}, C_{S O}(i)\right)+\cdots \\
& \mathrm{g}\left(q_{S S}(j) \times W_{S S} \times \cos \left(\varphi_{A}+v\right), C_{S S}(j), W_{S}, E, I_{Z S}, C_{S O}(i)\right)+\cdots \\
& \mathrm{g}\left(q_{S S}(\mathrm{~N}) \times W_{S S} \times \cos \left(\varphi_{A}+v\right), C_{S S}(\mathrm{~N}), W_{S}, E, I_{Z S}, C_{S O}(i)\right) \\
= & q_{S S}(1) \times W_{S S} \times \mathrm{g}\left(\cos \left(\varphi_{A}+v\right), C_{S S}(1), W_{S}, E, I_{Z S}, C_{S O}(i)\right) \\
& +q_{S S}(2) \times W_{S S} \times \mathrm{g}\left(\cos \left(\varphi_{A}+v\right), C_{S S}(2), W_{S}, E, I_{Z S}, C_{S O}(i)\right)+\cdots \\
& q_{S S}(j) \times W_{S S} \times \mathrm{g}\left(\cos \left(\varphi_{A}+v\right), C_{S S}(j), W_{S}, E, I_{Z S}, C_{S O}(i)\right)+\cdots \\
& q_{S S}(\mathrm{~N}) \times W_{S S} \times \mathrm{g}\left(\cos \left(\varphi_{A}+v\right), C_{S S}(\mathrm{~N}), W_{S}, E, I_{Z S}, C_{S O}(i)\right) \\
= & \sum_{j=1}^{N} q_{S S}(j) \times W_{S S} \times \mathrm{g}\left(\cos \left(\varphi_{A}+v\right), C_{S S}(j), W_{S}, E, I_{Z S}, C_{S O}(i)\right)
\end{aligned}
$$

With the same method, the roll $S$ deflection in $C_{S O}(i)$ position affected by $q_{S O}$ and $q_{S P}$ can be calculated by

$$
\begin{aligned}
D_{S_{-} q_{S O}}\left(C_{S O}(i)\right)= & \sum_{j=1}^{N} q_{S O}(j) \times W_{S O} \times g\left(-\cos \left(\alpha_{A}\right), C_{S O}(j),\right. \\
& \left.W_{S}, E, I_{Z S}, C_{S O}(i)\right) \\
D_{S_{-} q_{S P}}\left(C_{S O}(i)\right)= & \sum_{j=1}^{N} q_{S P}(j) \times W_{S P} \times g\left(-\cos \left(\varphi_{A}+\varphi_{B}+\alpha_{B}\right),\right. \\
& \left.C_{S P}(j), W_{S}, E, I_{Z S}, C_{S O}(i)\right)
\end{aligned}
$$

According to the Eq. (7), the roll $S$ flattening in $C_{S O}(i)$ position is as follows:

$$
R F_{S O}\left(C_{S O}(i)\right)=q_{S O}(i) \times F_{S O}(i)
$$

Thus, the deformation of roll $S$ in $C_{S O}(i)$ position is shown as

$$
\begin{aligned}
D_{S}\left(C_{S O}(i)\right)= & D_{S_{-} q_{S S}}\left(C_{S O}(i)\right)+D_{S_{-} q_{S O}}\left(C_{S O}(i)\right)+D_{S_{-} q_{S P}}\left(C_{S O}(i)\right) \\
& +R F_{S O}\left(C_{S O}(i)\right)
\end{aligned}
$$

In Fig. 3, the roll $\mathrm{O}$ deflection is affected by $q_{S O}, q_{O I}, q_{O J}$. With the Eq. (8), the roll $\mathrm{O}$ deflection in $C_{O S}(i)$ position affected by $q_{S O}, q_{O I}, q_{O J}$ can be calculated by Eqs. (14)-(16), respectively.

$$
\begin{aligned}
D_{S_{-} q_{S O}}\left(C_{O S}(i)\right)= & \sum_{j=1}^{N} q_{S O}(j) \times W_{S O} \\
& \times g\left(\cos \left(\alpha_{A}\right), C_{O S}(j), W_{O}, E, I_{Z O}, C_{O S}(i)\right)
\end{aligned}
$$




$$
\begin{aligned}
D_{S_{-} q_{O I}}\left(C_{O S}(i)\right)= & \sum_{J=1}^{N} q_{O I}(j) \times W_{O I} \times g\left(-\cos \left(\varphi_{C}+\alpha_{C}\right),\right. \\
& \left.C_{O I}(j), W_{O}, E, I_{Z O}, C_{O S}(i)\right) \\
D_{S_{-} q_{O J}}\left(C_{O S}(i)\right)= & \sum_{J=1}^{N} q_{O J}(j) \times W_{O J} \times g\left(-\cos \left(\varphi_{D}+\alpha_{D}\right),\right. \\
& \left.C_{O J}(j), W_{O}, E, I_{Z O}, C_{O S}(i)\right)
\end{aligned}
$$

From the Eq. (7), the roll $\mathrm{O}$ flattening in $C_{O S}(i)$ position is shown in Eq. (17).

$$
R F_{O S}\left(C_{O S}(i)\right)=q_{S O}(i) \times F_{O S}(i)
$$

So the deformation of roll $\mathrm{S}$ in $C_{S O}(\mathrm{I})$ position could be obtained.

$$
\begin{aligned}
D_{O}\left(C_{O S}(i)\right)= & D_{S_{-} q_{S O}}\left(C_{O S}(i)\right)+D_{S_{-} q_{O I}}\left(C_{O S}(i)\right)+D_{S_{-} q_{O J}}\left(C_{O S}(i)\right) \\
& +R F_{O S}\left(C_{O S}(i)\right)
\end{aligned}
$$

According to the coordination equation (Eq. (3)), the deformation coordination equation for the elements between the rolls $S$ and $O$ can be deduced as Eq. (19) with the Eqs. (13) and (18),

$$
\begin{aligned}
q_{S O}(i) & F_{S O}(i)+\sum_{j=1}^{N} q_{S S}(j) W_{S S} \mathrm{~g}\left(\cos \left(\varphi_{A}+v\right), C_{S S}(j), W_{S}, E, I_{Z S}, C_{S O}(i)\right) \\
& +\sum_{j=1}^{N} q_{S O}(j) W_{S O} \mathrm{~g}\left(-\cos \left(\alpha_{A}\right), C_{S O}(j), W_{S}, E, I_{Z S}, C_{S O}(i)\right) \\
& +\sum_{j=1}^{N} q_{S P}(j) W_{S P} \mathrm{~g}\left(-\cos \left(\varphi_{A}+\varphi_{B}+\alpha_{B}\right), C_{S P}(j), W_{S}, E, I_{Z S}, C_{S O}(i)\right) \\
= & q_{S O}(i) F_{O S}(i)+\sum_{j=1}^{N} q_{S O}(j) W_{S O} \mathrm{~g}\left(\cos \left(\alpha_{A}\right), C_{O S}(j), W_{O}, E, I_{Z O}, C_{O S}(i)\right) \\
& +\sum_{j=1}^{N} q_{O I}(j) W_{O I} \mathrm{~g}\left(-\cos \left(\varphi_{C}+\alpha_{C}\right), C_{O I}(j), W_{O}, E, I_{Z O}, C_{O S}(i)\right) \\
& +\sum_{j=1}^{N} q_{O J}(j) W_{O J} \mathrm{~g}\left(-\cos \left(\varphi_{D}+\alpha_{D}\right), C_{O J}(j), W_{O}, E, I_{Z O}, C_{O S}(i)\right) \quad(1 \leq i \leq N)
\end{aligned}
$$

The CEM matrix could been established on the basis of the deformation coordination functions between rolls $S$ and $O$ (Eq. (19)), $S$ and $P I$ and $O, J$ and $O$, roll $P$ and $J, P$ and $K, I$ and $A, I$ and $B, J$ and $B, J$ and $C, K$ and $C, K$ and $D$, and Eq. (4), and then the following ones can be solved: $q_{S S}, q_{S O}, q_{S P}, q_{O I}, q_{O J}, q_{P J}, q_{P K}, q_{I A}, q_{I B}, q_{J B}, q_{J C}, q_{K C}$, and $q_{K D}$.

2.2.6 Rolls Deflection in Sendzimir Mill. According to the rolling pressure (between the work roll and the strip) and the pressure between rolls: $q_{S S}, q_{S O}, q_{S P}, q_{O I}, q_{O J}, q_{P J}, q_{P K}, q_{I A}, q_{I B}, q_{J B}, q_{J C}, q_{K C}$ and $q_{K D}$, the deflection of all rolls can be gotten. Here, the deflection models of rolls $S, O, I, J, A, B$ are listed due to approximately symmetrical structure of the roll system.

2.2.6.1 Deflection of the roll $\mathrm{S}$ in $Y$ direction. Equation (20) represents the deflection distance of roll $\mathrm{S}$ in $C_{S O}(i)$ in the $Y$ direction

$$
\begin{aligned}
D_{\mathrm{FS}}( & \left.C_{S O}(i)\right) \\
& =\sum_{j=1}^{N} \mathrm{~g}\left(q_{S S}(j) \cos (v), C_{S S}(j), W_{S}, E, I_{Z S}, C_{S O}(i)\right) \\
& -\sum_{j=1}^{N} \mathrm{~g}\left(q_{S O}(j) \cos \left(\varphi_{A}-\alpha_{A}\right), C_{S O}(j), W_{S}, E, I_{Z S}, C_{S O}(i)\right) \\
& -\sum_{j=1}^{N} \mathrm{~g}\left(q_{S P}(j) \cos \left(\varphi_{B}+\alpha_{B}\right), C_{S P}(j), W_{S}, E, I_{Z S}, C_{S O}(i)\right) \quad(1 \leq i \leq N)
\end{aligned}
$$

2.2.6.2 Deflection of the roll $O$ in $O J$ direction. The deflection distance of roll $O$ in $C_{O S}(i)$ in the $O J$ direction is described by

$$
\begin{aligned}
D_{\mathrm{FO}}( & \left.C_{O S}(i)\right) \\
= & \sum_{j=1}^{N} \mathrm{~g}\left(q_{S O}(j) \cos \left(\alpha_{A}\right), C_{O S}(j), W_{O}, I_{Z O}, C_{O S}(i)\right) \\
& -\sum_{j=1}^{N} \mathrm{~g}\left(q_{O I}(j) \cos \left(\varphi_{C}+\alpha_{C}\right), C_{O I}(j), W_{O}, I_{Z O}, C_{O S}(i)\right) \\
& -\sum_{j=1}^{N} \mathrm{~g}\left(q_{O J}(j) \cos \left(\varphi_{D}+\alpha_{D}\right), C_{O J}(j), W_{O}, I_{Z O}, C_{O S}(i)\right) \quad(1 \leq i \leq N)
\end{aligned}
$$




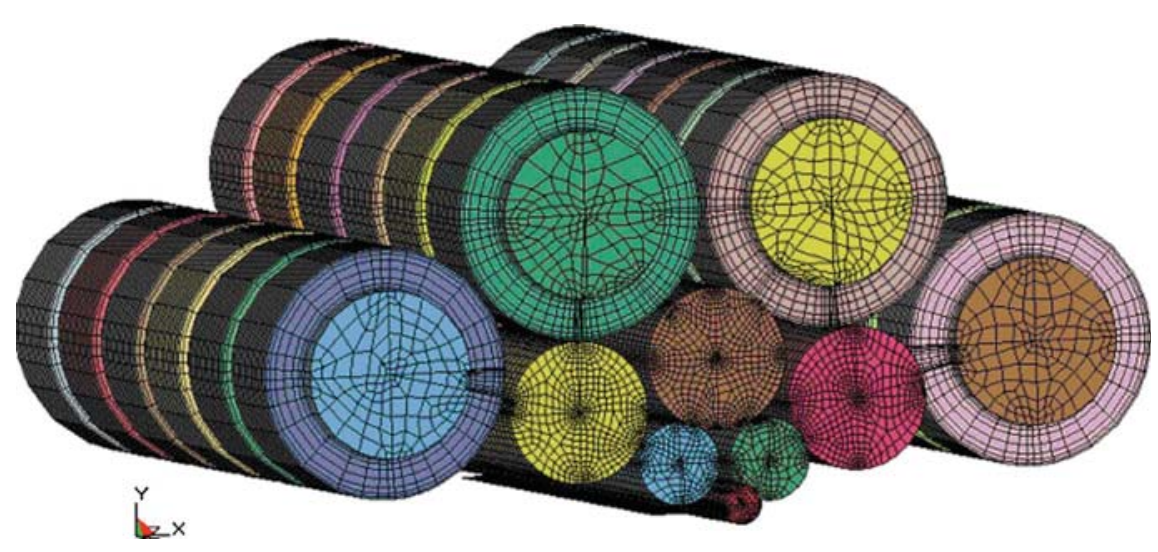

Fig. 4 Geometry and FE meshing of Sendzimir mill

2.2.6.3 Deflection of the roll I in IO direction. Equation (22) displays the deflection distance of roll $I$ in $C_{I O}(i)$ in the $I O$ direction

$$
\begin{aligned}
D_{\mathrm{FI}}( & \left.C_{I O}(i)\right) \\
= & \sum_{j=1}^{N} \mathrm{~g}\left(q_{O I}(j) \cos \left(\alpha_{C}\right), C_{I O}(j), W_{I}, I_{Z I}, C_{I O}(i)\right) \\
- & \sum_{j=1}^{N} \mathrm{~g}\left(q_{I A}(j) \cos \left(\varphi_{G}+\alpha_{G}\right), C_{I A}(j), W_{I}, I_{Z I}, C_{I O}(i)\right) \\
- & \sum_{j=1}^{N} \mathrm{~g}\left(q_{I B}(j) \cos \left(\varphi_{H}-\alpha_{H}\right), C_{I B}(j), W_{I}, I_{Z I}, C_{I O}(i)\right) \\
& (1 \leq i \leq N)
\end{aligned}
$$

2.2.6.4 Deflection of the roll $J$ in the $Y$ direction. The deflection distance of roll $J$ in $C_{J O}(i)$ in the $Y$ direction is given

$$
\begin{aligned}
D_{\mathrm{FJ}}\left(C_{J O}(i)\right) & \\
= & \sum_{j=1}^{N} \mathrm{~g}\left(q_{O J}(j) \cos \left(\varphi_{D}-\varphi_{A}\right), C_{J O}(j), W_{J}, I_{Z J}, C_{J O}(i)\right) \\
+ & \sum_{j=1}^{N} \mathrm{~g}\left(q_{P J}(j) \cos \left(\varphi_{E}-\varphi_{A}\right), C_{J P}(j), W_{J}, I_{Z J}, C_{J O}(i)\right) \\
- & \sum_{j=1}^{N} \mathrm{~g}\left(q_{J B}(j) \cos \left(\varphi_{I}+\alpha_{I}\right), C_{J B}(j), W_{J}, I_{Z J}, C_{J O}(i)\right) \\
- & \sum_{j=1}^{N} \mathrm{~g}\left(q_{J C}(j) \cos \left(\varphi_{J}-\alpha_{J}\right), C_{J C}(j), W_{J}, I_{Z J}, C_{J O}(i)\right) \\
& (1 \leq i \leq N)
\end{aligned}
$$

2.2.6.5 Deflection of the roll $A$ in IA direction. Equation (24) shows the deflection distance of roll $A$ in $C_{A I}(i)$ in the $I A$ direction

$$
\begin{gathered}
D_{\mathrm{FA}}\left(C_{A I}(i)\right)=\sum_{j=1}^{N} \mathrm{~g}\left(q_{I A}(j) \cos \left(\alpha_{G}\right), C_{A I}(j), W_{A}, I_{Z A}, C_{A I}(i)\right) \\
(1 \leq i \leq N)
\end{gathered}
$$

2.2.6.6 Deflection of the roll $B$ in the $I B$ direction. Equation (25) shows the deflection distance of roll $B$ in $C_{B I}(i)$ in the $I B$ direction

$$
\begin{aligned}
D_{\mathrm{FB}}\left(C_{B I}(i)\right) \\
=\sum_{j=1}^{N} \mathrm{~g}\left(q_{I B}(j) \cos \left(\alpha_{H}\right), C_{B I}(j), W_{B}, I_{Z B}, C_{B I}(i)\right) \\
+\sum_{j=1}^{N} \mathrm{~g}\left(q_{J B}(j) \cos \left(\varphi_{H}-\left(\varphi_{C}+\varphi_{D}\right) / 2\right), C_{B J}, W_{B}, I_{Z B}, C_{B I}(i)\right) \\
\quad(1 \leq i \leq N)
\end{aligned}
$$

\section{Numerical Results and Analysis}

3.1 Parameters for Computation. The numerical software SM4SM is developed based on the models above, by which the rolls deflection in any condition can be analyzed. The basic parameters in analyzing process are shown in Table 1.

3.2 FE Model. The FE model is built to check the results calculated by SM4SM with the parameters in Table 1. Owing to the symmetry of rolls system, the above ten rolls (rolls $A-D, I-K$, $O, P, S)$ are included in the geometric model. During simulation, the necks of backup rolls constrained by $A S-U$ racks are considered rigid and are constrained, $U_{x, y, z}=0$. Other parts are considered as elastic parts, and the nodes at rolls end are constrained, $U_{x, y, z}=0$. The rolls' models are meshed by the eight nodes and

Table 1 General rolling conditions and parameters for computation

\begin{tabular}{lc}
\hline \hline Parameters & Value \\
\hline Diameter of rolls $A, B, C, D, \mathrm{~mm}$ & 406.4 \\
Diameter of rolls $I, J, K, \mathrm{~mm}$ & 235.0 \\
Diameter of rolls $O, P, \mathrm{~mm}$ & 140.0 \\
Diameter of roll $S, \mathrm{~mm}$ & 75.0 \\
Backing bearing width of rolls $A, B, C, D, \mathrm{~mm}$ & 171.0 \\
Saddles width of rolls $A, B, C, D, \mathrm{~mm}$ & 64.0 \\
Barrel length of rolls $I, J, K, \mathrm{~mm}$ & 1450.0 \\
Barrel length of rolls $O, P, \mathrm{~mm}$ & 1500.0 \\
Barrel length of roll $S, \mathrm{~mm}$ & 1677.0 \\
Strip entry thickness, mm & 2.0 \\
Strip exit thickness, mm & 1.4 \\
Strip width, mm & 1035.0 \\
Friction coefficient & 0.05 \\
Young's modulus of strip, MPa & $2.06 \times 10^{5}$ \\
Mean deformation resistance of strip, MPa & 680.0 \\
Poisson's ratio & 0.3 \\
Young's modulus of rolls, MPa & $2.6 \times 10^{5}$ \\
Back tension, MPa & 120.0 \\
Front tension, MPa & 140.0 \\
\hline \hline
\end{tabular}




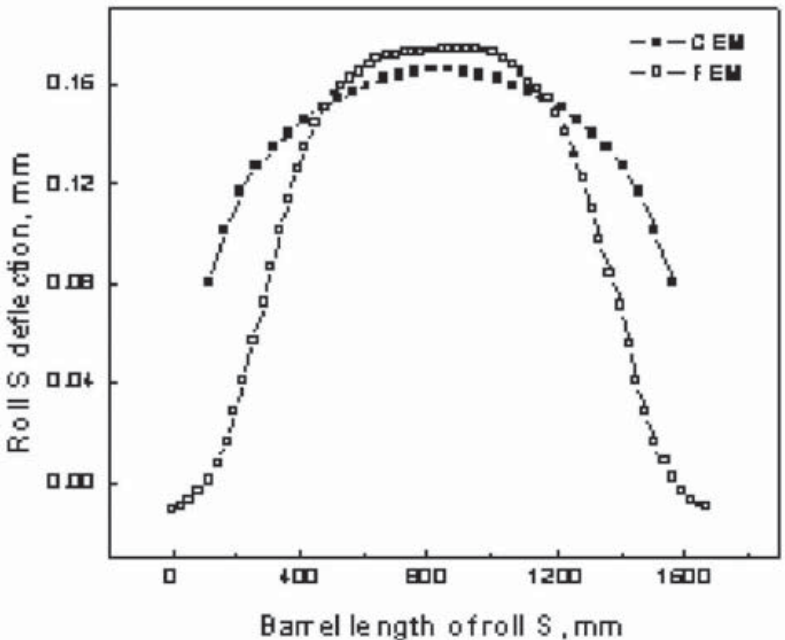

(a)

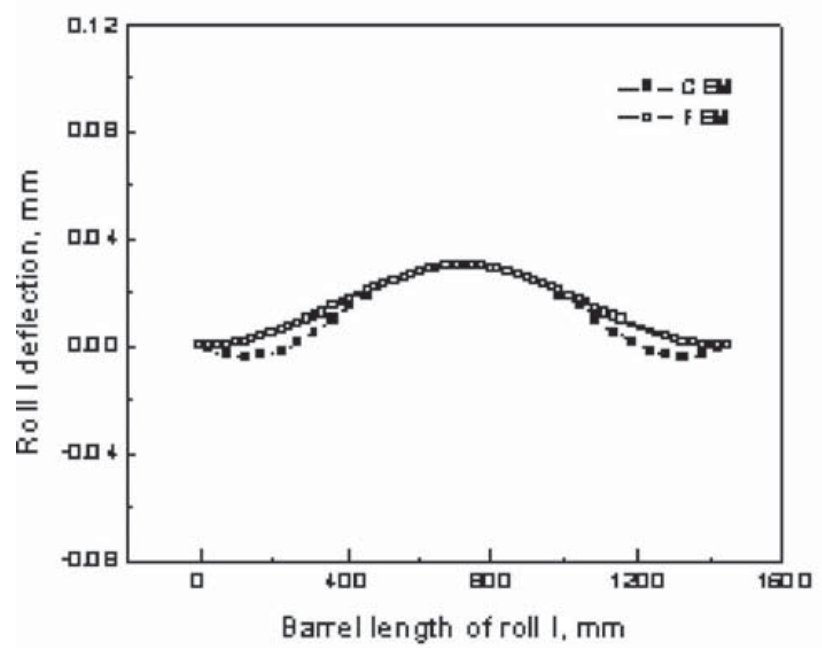

(5)

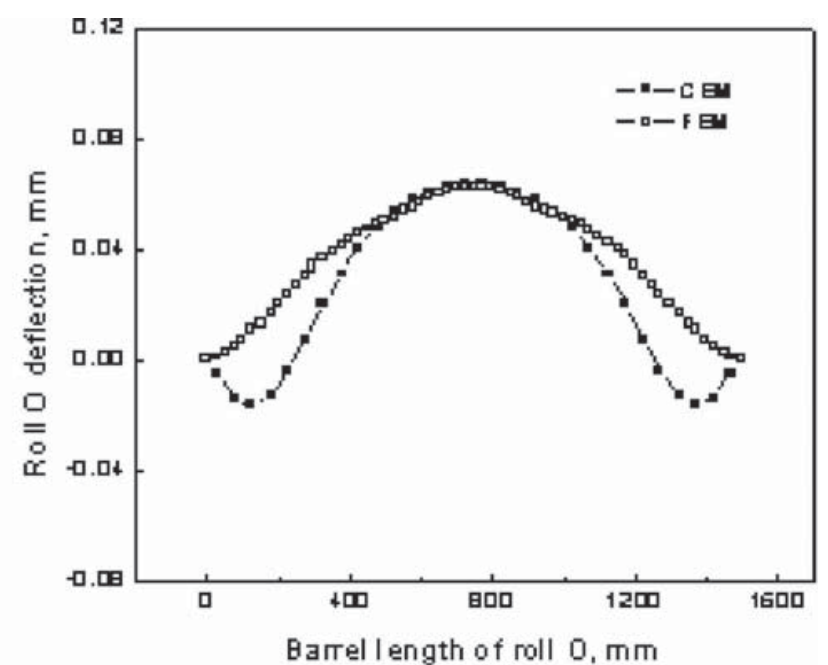

(b)

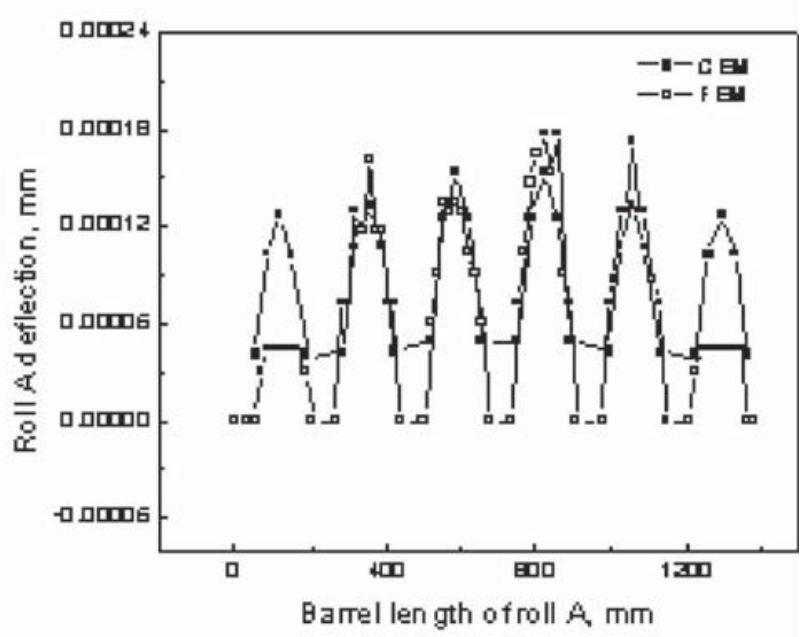

(4)

Fig. 5 Roll deflection: (a) roll $S,(b)$ roll $O,(c)$ roll $I$, and (d) roll $A$

hexahedron elements, and the elements near contact positions between rolls are refined (in simulation, there are 42 pairs of contacts). The rolling pressure is loaded when the strip enters the roll gap. The geometrical model and meshing of rolls system is shown in Fig. 4.

3.3 Calculation Results. Figure 5 shows the deflection curve of rolls in Sendzimir mill by CEM and FEM, and the results by CEM are similar to that obtained by FEM. As shown in Fig. 5, it is rather apparent that the deflection of roll $S$ is the largest. Moreover, the deflection of $\operatorname{roll} A$ is the smallest.

In Eqs. (20)-(25), the roll deflection is mainly determined by the pressure distribution between rolls on roll surface for Sendzimir mill. The influence factors, which include roll assignment, $A S-U$ rack position, roll $J$ profile, the first IMR shift and taper slope and length, strip profile and deformation resistance, reduction ratio, etc., remarkably affect the pressure distribution between rolls.

In production, the roll assignment, the first IMR taper length and slope, the rolling schedule generally could not be changed. Thus, it needs to adjust the roll deflection so as to adjust the $A S$ $U$ rack position and the first IMR shift. There is no doubt that the work roll deflection affects the strip profile directly, and then will affect the quality and production ratio of product. Figure 5(a) shows the work roll deflection in common condition. With this kind of roll deflection, the strip exit crown will be too large to produce the qualified product. Thus, it needs to adjust the $A S-U$ rack position and first IMR shift for obtaining suitable roll deflection during rolling process. With the calculated roll deflection and flattening, the strip profile could be obtained. Figure 6 shows the strip profile under certain rolling conditions for a Sendzimir mill with double $A S$ - $U$-roll systems, where the formerly calculated strip exit profile is acted as the strip enter profile in the next pass.

\section{Conclusions}

1. A new numerical analysis method, the contact element method with two relative coordinates (CEM), has been developed. The main features of the procedure are that meshing depends on the contact length between objects and that each element has two relative coordinates. The ordinary expression of this procedure is $D_{X}\left[C_{X Y}(i)\right]=D_{Y}\left[C_{Y X}(i)\right]$.

2. Through the contact element method with two relative coordinates, the CEM function of a 20-high Sendzimir mill and the deflection function expressions of every roll are obtained. The computational software SM4SM (setup models for Sendizimir mill) is developed with the functions deduced through CEM function, by which the deflection condition of every roll can be calculated. 


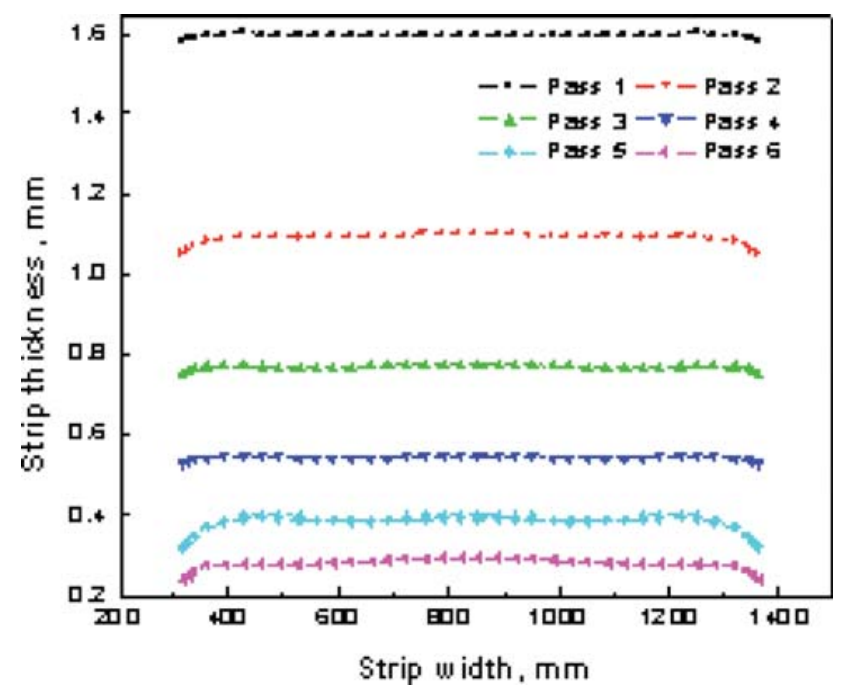

Fig. 6 Strip profile calculated by SM4SM

\section{Acknowledgment}

The authors gratefully acknowledge the financial supports from POSCO and National Natural Science Foundation of China through Grant No. 50534020. Authors also thank Prof. Chen Liqing and Mrs. Xue Wenying for their assistance in preparing this manuscript.

\section{Nomenclature}

$b=$ half of the contact width between flattened rolls

$C_{S S}(i)=$ relative coordinate based on the roll $S$ between the roll $S$ and the strip of element $i$

$C_{X Y}(i)=$ relative coordinate based on the roll $X$ between the rolls $X$ and $Y$ of element $i$, which contains $C_{S O}(i), C_{O S}(i), C_{O I}(i), C_{I O}(i), C_{O J}(i), C_{J O}(i)$, $C_{P J}(i), C_{J P}(i), C_{P K}(i), C_{K P}(i), C_{I A}(i), C_{A I}(i)$, $C_{I B}(i), C_{B I}(i), C_{J B}(i), C_{B J}(i), C_{J C}(i), C_{C J}(i)$, $C_{K C}(i), C_{C K}(i), C_{K D}(i), C_{D K}(i)$

$D_{X}\left[C_{X Y}(i)\right]=$ deformation of roll $X$ between rolls $X$ and $Y$ in $C_{X Y}(i)$

$D_{F X}\left[C_{X Y}(i)\right]=$ deflection of the roll $X$ in $X Y$ direction in $C_{X Y}(i)$, which contains $D_{\mathrm{FA}}\left(C_{A I}(i)\right)$, $D_{\mathrm{FB}}\left(C_{B I}(i)\right), D_{\mathrm{FI}}\left(C_{I O}(i)\right), D_{\mathrm{FO}}\left(C_{O S}(i)\right)$. And $D_{\mathrm{FJ}}\left(C_{S J}(i)\right), D_{\mathrm{FS}}\left(C_{S J}(i)\right)$ are in the $S J$ direction

$D_{X_{-} q_{x y}}\left(C_{X Y}(i)\right)=$ deflection of roll $X$ in $X Y$ direction in $C_{X Y}(i)$ caused by $q_{x y}$

$E, E_{K}, E_{K}^{\prime}=$ Young's modulus of the roll, $\mathrm{MPa}$

$f=$ friction coefficient between the roll and the strip

$F=$ assembling force, $\mathrm{N}$

$F_{X Y}(i)=$ elastic flattening of the roll $X$ between the rolls $X$ and $Y$, which contains $F_{S O}(i), F_{O I}(i), F_{O J}(i)$, $F_{P J}(i), F_{P K}(i), F_{I A}(i), F_{I B}(i), F_{J B}(i), F_{J C}(i)$, $F_{K C}(i), F_{K D}(i)$

$h_{c p}=$ mean thickness of the strip in the rolling deformation zone, $\mathrm{mm}$
$I_{Z}, I_{Z X}=$ inertia moment of the roll $X$, which contains $I_{Z S}, I_{Z O}, I_{Z P}, I_{Z I}, I_{Z J}, I_{Z K}, I_{Z A}, I_{Z B}, I_{Z C}, I_{Z D}$

$K=$ mean resistance of deformation of the strip, $\mathrm{MPa}$

$l=$ horizontal project of the contact arc as the roll is elastically flattened

$L=$ barrel length of rolls, $\mathrm{mm}$

$l_{1}=$ distance between the position acted by the assembling force and one end of the roll, $\mathrm{mm}$

$\mathrm{N}=$ element quantity

$P=$ pressure between rolls, $\mathrm{MPa}$

$P_{N P}=$ rolling force, $\mathrm{N}$

$P_{X}=$ component force of the roll system, which contains $P_{A}, P_{B}, P_{C}, P_{D}, P_{E}, P_{F}, P_{G}, P_{H}, P_{I}$, $P_{J}, P_{K}, P_{L}$

$q_{X Y}(j)=$ pressure acted on element $j$ between the rolls $X$ and $Y$, which contain $q_{S O}(j), q_{S P}(j), q_{O I}(j)$, $q_{O J}(j), q_{P J}(j), q_{P K}(j), q_{I A}(j), q_{I B}(j), q_{J B}(j)$, $q_{J C}(j), q_{K C}(j), q_{K D}(j)$

$q_{S S}(j)=$ pressure acted on element $j$ between the roll $S$ and the strip

$R, R_{K}, R_{K}^{\prime}=$ roll diameter, $\mathrm{mm}$

$t_{c p}=$ mean unit tension of the strip in rolling, $\mathrm{MPa}$

$W_{X Y}=$ element width between the rolls $X$ and $Y$, which contains $W_{S O}, W_{S P}, W_{O I}, W_{O J}, W_{P J}$, $W_{P K}, W_{I A}, W_{I B}, W_{J B}, W_{J C}, W_{K C}, W_{K D}$

$W_{S S}=$ element width between the strip and the work roll

$W_{\text {strip }}=$ strip width (the contact length between the strip and the work roll is equal to $W_{\text {strip }}$ because the width of strip is less than the barrel length of work roll)

$W_{X}=$ barrel length of rolls, which contains $W_{S}, W_{O}$, $W_{P}, W_{I}, W_{J}, W_{K}, W_{A}, W_{B}, W_{C}, W_{D}$

$\alpha_{X}=$ friction angle between rolls, which contains $\alpha_{A}$ $\sim \alpha_{L}$

$\varphi_{A} \sim \varphi_{L}=$ angle between rolls center

$\sigma, \sigma_{K}, \sigma_{K}^{\prime}=$ Poisson's ratio of the roll

\section{References}

[1] Schneider, A., and Werners, R., 1999, "Modeling and Optimization for a 20-h Cold Rolling Mill," Iron Steel Eng., 76, pp. 44-47.

[2] Berger, B., Schulte, H., Benfer, M., and Rinke, F. W., 2000, "Advanced 20High Mill Technology,” MPT, Metall. Plant Technol. Int., 23(6), pp. 70-72, 74.

[3] Dutton, K., 1983, "An Investigation Into the Design and Performance of an Automatic Shape Control System for a Sendzimir Cold Rolling Mill,” British Steel Corp.

[4] Gunawardene, G. W. D. M., 1982, "A Static Model of a Sendzimir Mill for Use in Shape Control," British Steel Corp.

[5] Knapiński, M., 2006, "The Numerical Analysis of Roll Deflection During Plate Rolling," J. Mater. Process. Technol., 175, pp. 257-265.

[6] Jiang, Z. Y., Tieu, A. K., Zhang, X. M., Lu, C., and Sun, W. H., 2003, "Finite Element Simulation of Cold Rolling of Thin Strip," J. Mater. Process. Technol., 140, pp. 542-547.

[7] Yuen, W. Y. D., Duval, A., and Wechner, B., 1998, "A New Formulation for the Analysis of Strip Flatness in Strip Rolling," Steel Rolling's 98, Chiba, Japan, The Iron and Steel Institute of Japan, pp. 296-301.

[8] Xiong, S., Liu, X., and Wang, G., 2000, "Analysis of Non-Steady State Slab Edging in Roughing Trains by a Three-Dimensional Rigid-Plastic Finite Element Method,” Int. J. Mach. Tools Manuf., 40(11), pp. 1573-1585.

[9] Yu, H., Liu, X., Zhao, X., and Kusaba, Y., 2006, "FEM Analysis for V-H Rolling Process by Updating Geometric Method," J. Mater. Process. Technol., 180(1-3), pp. 323-327.

[10] Pan, C., 2003, 20-High Mill and High Precision of Cold Strip Rolling Production, Metallurgical Industry Press, Beijing. 